\title{
Aminoff Suffering Syndrome in Advanced Alzheimer's Disease and End-of-Life: First 10 Years
}

\author{
Bechor Zvi Aminoff MD, PhD ${ }^{1,2^{*}}$
}

${ }^{1}$ The Minerva Center for the Interdisciplinary Study of End-of-Life, Tel Aviv University, Ramat Aviv, Israel

${ }^{2}$ Geriatric Division, The Chaim Sheba Medical Center, Tel Hashomer, Israel

*Corresponding Author: Dr. Bechor Zvi Aminoff, MD, PhD, Research Professor, Shamay St. 26, Fl. 2, El Ad, 40800, Israel; Tel: 972-54-2450244; E-mail: bechorz@yahoo.com Website: www.aminoff-end-of-life-suffering-happiness.co.il

\begin{abstract}
The Aminoff Suffering Syndrome in advanced Alzheimer disease and endof-life is characterized by a high Mini Suffering State Examination (MSSE) scale score, less than 6 months survival, irreversible and intractable aggravation of suffering and actively dying medical condition until demise. The Aminoff Suffering Syndrome was first defined by us, presented and published 10 years ago in the $10^{\text {th }}$ International Conference on Alzheimer's disease and Related Disorders (Madrid, 2007). Its diagnosis in end-of-life was performed by measuring the suffering level of patients by evaluating the Mini Suffering State Examination (MSSE) scale score. The treatment of patients with Aminoff Suffering Syndrome at the end of life is a great challenge to medical and nursing personnel. The diagnosis of Aminoff Suffering Syndrome opens new horizons in the approach to anguish at end-of-life and provides a novel method for identifying advanced Alzheimer's disease patients that require immediate palliative treatment.
\end{abstract}

Keywords: Advanced Alzheimer disease; End of life; Aminoff suffering syndrome; relief of suffering units; Palliative care.

Abbreviation: ASS: Aminoff Suffering Syndrome, MSSE: Mini Suffering State Examination, SM-EOLD: Symptom Management in End-of-Life in Dementia; CAD-EOLD: Comfort Assessment in Dying with Dementia
Received Date: July 31, 2017

Accepted Date: November 13, 2017

Published Date: November 15, 2017

Citation: Aminoff, B.Z. Aminoff Suffering Syndrome in Advanced Alzheimer's Disease and End-of-Life: First 10 Years. (2017) Lett Health Biol Sci 2(2): 86- 90.

DOI: $10.15436 / 2475-6245.17 .021$

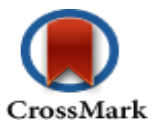

Quote: The suffering of patients is not a function of disease; it is a function of inadequate medical and nursing care ${ }^{[1]}$.

\section{Introduction}

Several important questions await experimental evidence from well-validated clinical studies performed on patients at the end-of-life. Such questions include:

1) How is the suffering level of patients who are enrolled in palliative care measured?

2) Does palliative care successfully reduce and alleviate human suffering until demise?

3) Which are the best validated tools for evaluating the suffering level at the end of life, that is, from diagnosis of suffering before and during palliative care, and until demise?

4) What is the best approach for diagnosing short survival at the end of life?
Undoubtedly, additional questions still remain to be answered.

According to the results of a prospective clinical study on measuring the level of suffering at the advanced Alzheimer disease and end of life, a new clinical and pathological entity was defined, that is, Aminoff Suffering Syndrome. The data were presented at world and international congresses in Madrid, Saint-Petersburg, Trondheim, Paris, Honolulu, Athens, Copenhagen, Seoul and Edinburgh. The Aminoff Suffering Syndrome raises a lot of interest in the scientific literature ${ }^{[2-5]}$.

\section{Aminoff Suffering Syndrome (ASS)}

The Aminoff Suffering Syndrome in advanced dementia is characterized by a high Mini Suffering State Examination

Copyrights: (C) 2017 Aminoff, B.Z. This is an Open access article distributed under the terms of Creative Commons Attribution 4.0 International License. 
(MSSE) scale score, less than 6 months survival, irreversible and intractable aggravation of suffering and actively dying medical condition until demise ${ }^{[6-9]}$.

In the year 1907, Dr Alois Alzheimer published a famous case report on Mrs Auguste Deter ${ }^{[10]}$. In an article published in 2013, the authors ${ }^{[11]}$ were able to establish that Mrs Deter suffered from Aminoff Suffering Syndrome. The last months, weeks and days of Mrs Auguste Deter's life was in high suffering level by MSSE and definitely in Aminoff Suffering Syndrome with the description of her medical history and follow up which was reported by Dr. Alois Alzheimer in 1906.

\section{Mini Suffering State Examination scale (MSSE)}

The MSSE (Table 1) scale ${ }^{[12,13]}$ is the first objective clinical tool for the evaluation of suffering level in advanced dementia. The MSSE scale finds extensive use in medical research ${ }^{[14-17]}$ and practice ${ }^{[18-21]}$. The MSSE scale is available in English, Hebrew, Dutch ${ }^{[22]}$, Germane, Italian, Spanish and Slovenian ${ }^{[23]}$, and covers 10 items (range 0 - 10). A high MSSE scale score with range of 7 - 10 indicates a high level of suffering, and reflects the severity of the medical condition in advanced dementia.

Table 1: The level of suffering in a patient with end-stage dementia can be diagnosed objectively by means of a Mini Suffering State Examination (MSSE) consisting of 10 questions.

\begin{tabular}{|l|l|l|l|}
\hline & Suffering State & YES - 1 & NO - 0 \\
\hline 1 & Not calm & & \\
\hline 2 & Screams & & \\
\hline 3 & Pain & & \\
\hline 4 & Decubitus ulcers & & \\
\hline 5 & Malnutrition & & \\
\hline 6 & Eating disorders & & \\
\hline 7 & Invasive action & & \\
\hline 8 & Unstable medical condition & & \\
\hline 9 & Suffering according to medical opinion & & \\
\hline 10 & Suffering according to family opinion & & \\
\hline & MSSE score & & \\
\hline
\end{tabular}

\section{The MSSE Score Interpretation:}

$\begin{array}{ll}\text { Low level of suffering } & 0-3 \\ \text { Intermediate level of suffering } & 4-6 \\ \text { High level of suffering } & 7-10\end{array}$

A high MSSE score indicates a high level of suffering. The MSSE can be used as a diagnostic tool in the treatment and prevention of suffering in a patient with end-stage dementia. The well-being of an end-stage dementia patient is in inverse proportion to his level of suffering. The end-stage dementia patient with a low MSSE score has a good quality of life.

The MSSE scale was tested using the Cronbach $\alpha$ model, which demonstrated its significant reliability $(\alpha=0.798)$. A $\kappa$ agreement coefficient of 0.791 between two observers was found. Both observers found a significant association between the three MSSE levels and age $(\mathrm{P}=0.02)$, haemoglobin $(\mathrm{P}=$ $0.02)$, albumin $(\mathrm{P}<0.001)$, cholesterol $(\mathrm{P}=0.04)$, use of analgesics or antipsychotics $(\mathrm{P}=0.04)$.

The convergent validity of the MSSE scale was proven by Pearson correlation with Symptom Management in End-ofLife Dementia (SM-EOLD) scale $(r=0.574, \mathrm{P}<0.0001)$ and
Comfort Assessment in Dying with Dementia (CAD-EOLD) $\operatorname{scale}^{[24]}(r=-0.796, P<0.0001)$. The mean survival of end-stage dementia patients with a low MSSE scale score $(\mathrm{MSSE}=2.24$ \pm 0.99 ) was $57.76 \pm 9.73$ days, and with a median MSSE scale score $(\mathrm{MSSE}=4.92 \pm 0.83)$, the mean survival was $44.70 \pm$ 5.99 days. In the high MSSE scale score group (MSSE $=8.06 \pm$ $1.00)$, mean survival was much lower $(27.54 \pm 4.16 \text { days })^{[25]}$.

The differences between the survival times of the three MSSE scale score groups was evaluated by Kaplan-Meier analysis (Log Rank, $\mathrm{P}=0.0018$, Breslow, $\mathrm{P}=0.0027$ ) and were significant (Figure 1). The results of the Cox proportional Hazard model of survival showed a high correlation between high MSSE scale score and high risk of mortality, and short survival of end-stage dementia patients during the last 6 months of life with significant predicting validity $(\mathrm{P}=0.013)^{[26]}$.

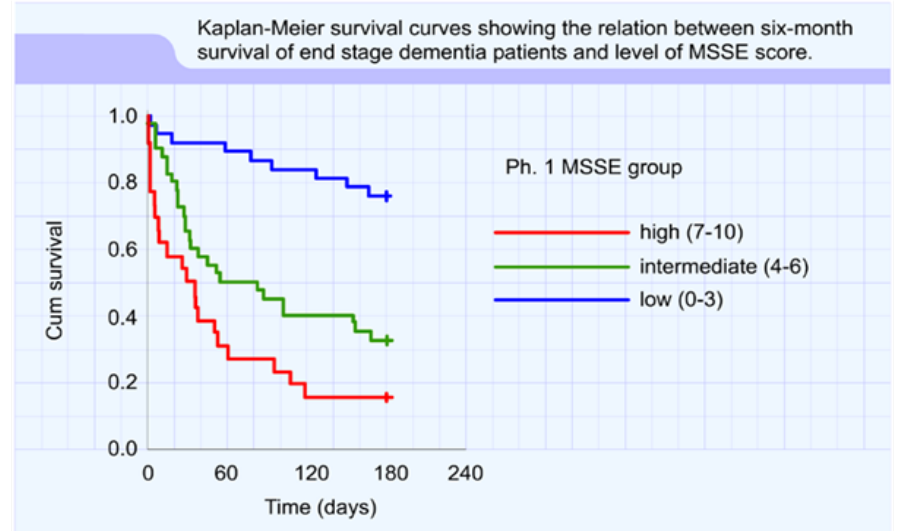

Figure 1: Kaplan-Meier survival curves showing the relation between six-month survival of end-stage dementia patients and level of MSSE score.

Seventy-one end stage dementia patients have been studied.

The difference between the survival curves of the three groups of patients was statistically significant: Log Rank (Mantel-Cox) $\mathrm{P}=0.001$; Breslow Test (Generalized Wilcoxon) $\mathrm{P}=$ 0.001

According to the MSSE scale, it was confirmed that patients with end-stage dementia represent a heterogeneous group and have different levels of suffering, and accordingly proved a significant concurrent validity. The results of the current research showed that hospitalization in the geriatric department of a tertiary hospital in Israel failed to reduce the high level of suffering of such patients. The total score of the MSSE scale of advanced dementia patients, on the day of admission to the geriatric department was $5.62 \pm 2.31$, and increased to $6.89 \pm 1.95$ on the last day of life with a significant test-retest reliability $(\mathrm{P}<$ $0.0001)^{[27]}$.

Despite traditional medical and nursing care, a large proportion of dying patients with dementia experienced increased suffering as they approached death. According to the MSSE scale, 63.4 and $29.6 \%$ experienced high and intermediate levels of suffering, respectively, with only $7 \%$ having a low level of suffering upon their demise ${ }^{[28]}$.

On the last day of life, $71.8 \%$ of dying patients with dementia and Aminoff Suffering Syndrome were not calm, 71.4\% had decubitus ulcers, $94.4 \%$ suffered from malnutrition, $95.8 \%$ had eating disorders, $90.1 \%$ experienced invasive procedures and $90.1 \%$ were in an unstable medical condition. The suffering level in advanced dementia has a significant correlation with 
short survival, advancing age, more severe illness, malnutrition, the existence of decubitus ulcers and the administration of medications $^{[28]}$

\section{Discussion}

The life of patients with end-stage dementia is filled with grief, secretion and stench, suppuration and wounds, crying, screaming or silent pain. This appears to be the natural and essential path of end-stage disease and aging. In the modern world, despite advanced medical science, the society at large is not always aware of the terrible suffering of elderly people in the last stage of life ${ }^{[6]}$.

The world outside the confines of the hospital is unaware of what transpires in the wards of hospitals and nursing homes. This also applies to other tragic circumstances.

Physicians and nursing staff facing day and night with difficult and exhausting tasks. Despite the difficulty in coping, it appears that medical personals have accepted this dreadful process of death. The patients' families are not always aware of this reality. Those who are in fact aware of the seriousness of the patient's condition, often distance themselves from the hospital and its environs. Others may engage in harsh altercations with the medical staff responsible for treatment.

Medicine today facilitates extended longevity at a high price of suffering to the patients, their families, and even to the medical professionals. It is easy to calculate the daily and annual costs of hospitalization. The maintenance costs are enormous over such an extended period. In the future, with increasing successes in the treatment of heart diseases and tumors, patients with dementia may well be the majority in hospital departments. One of the suggestions is preventing avoidable hospital admissions for people with advanced dementia ${ }^{[29]}$.

The perpetual and increased agony of an end-stage dementia patient is reminiscent of the suffering of patients prior to the era of anaesthesia or antibiotics. The main causes of suffering at the end-of-life are inadequate medical and nursing care, overprotection phenomenon with dying patients ${ }^{[30,31]}$ and Geriatrics D refusal phenomenon ${ }^{[32]}$.

Possible solutions to suffering at the end of life include measuring the level of suffering, and enrolment of patients diagnosed with Aminoff Suffering Syndrome to homes or hospital palliative care settings, or alternatively to Relief of Suffering Units $^{[33,34]}$ within hospitalization departments. The Relief of Suffering Units that can perform daily medical task without any new pecuniary or equipment expense should switch from futile intensive medical care to intensive nursing care. Intensive nursing care could prevent and relieve suffering at the end-of-life by a more meticulous approach to symptoms of not calm, screams and pain, decubitus ulcers, malnutrition and eating disorders, and thus obviate futile invasive action. Special vigilance and tenderness, warm hands, constant surveillance of the dying patient and intensive professional nursing care are challenges for nursing staff, and are a guarantee for relief and prevention of suffering at the end of life.

The suffering assessment ${ }^{[35-39]}$ and quality of dying evaluation $^{[40,41]}$ are important at the end of life. Some available instruments developed for suffering assessment in end of life are: Initial assessment of suffering ${ }^{[42]}$, Pictorial Representation of Illness and Self Measure ${ }^{[43]}$, Suffering Assessment Tool ${ }^{[44]}$,
State of Suffering-V ${ }^{[45]}$, The Suffering Scales ${ }^{[46]}$, and Structured Interview for Symptoms and Concerns Scale ${ }^{[47]}$.

The outcomes assessed in palliative care involve symptoms, physical signs, laboratory tests, evaluation scales, questionnaires for activities of daily living or quality-of-life, in order to interpret the quality of provided care ${ }^{[48,49]}$. Unfortunately, the overall reporting rate for the validation of articles in palliative care journals is only $1.43 \%{ }^{[50]}$, and there is a paucity of studies on patient-centered validation methods.

\section{Proposals}

The authors appeal to all medical researchers involved in geriatric care to perform experimental prospective studies in their respective clinical settings:

1. Diagnosis of Aminoff Suffering Syndrome in end-of-life patients with cancers and other malignant neoplasms.

2. Diagnosis of Aminoff Suffering Syndrome in end-of-life patients with AIDS, heart, kidney, pulmonary and liver diseases. 3. Measurement of suffering level by diagnosis of Aminoff Suffering Syndrome on the day of admission and on the last day of life to evaluate effectiveness of treatment in a hospice setting. 4. Routine diagnosis of Aminoff Suffering Syndrome in geriatric, internal medicine, surgery and other departments for subsequent enrolment of patients in palliative care or Relief of Suffering Units.

\section{Conclusion}

Aminoff Suffering Syndrome awaits its wide use in medicine ${ }^{[51]}$. Its diagnosis could reduce the suffering of patients at the end of life by adequate medical and nursing care ${ }^{[52]}$. Dealing with Aminoff Suffering Syndrome at the end of life provides a genuine challenge to nursing and medical personnel ${ }^{[53]}$.

Conflict of Interest: The author declares that there is no potential conflict of interest with respect to the research, authorship, and/or publication of this article. 


\section{References}

1. Aminoff, B.Z. Prognosis of short survival in patients with advanced dementia as diagnosed by Aminoff Suffering Syndrome. (2014) Am J Alzheimers Dis Other Demen 29(8): 673-677.

Pubmed | Crossref | Others

2. Block Van den, L., Albers, G., Pereira, S.M., et al. Palliative care for older people. A public health perspective. (2015) Oxford Scholarship Online.

Pubmed $\mid$ Crossref $\mid$ Others

3. Cipriani, G., Danti, S., Carlesi, C. Three men in a (same) boat: Alzheimer, Pick, Lewy. Historical notes. (2016) European Geriatric Medicine.

Pubmed | Crossref | Others

4. Hanson, E., Hellström, A., Sandvide, A. The extended palliative phase of dementia - An integrative literature review. (2016) Dementia. Pubmed | Crossref | Others

5. Garrett, M.D., Valle, R. A century of confusion in researching Alzheimer's disease. (2016) International Journal of Healthcare 2(2).

Pubmed | Crossref | Others

6. Aminoff, B.Z. Measurement of Suffering in End-Stage Alzheimer's Disease. (2007) Tel Aviv Probook Dyonon.

Pubmed $\mid$ Crossref $\mid$ Others

7. Aminoff, BZ. Aminoff Suffering Syndrome: A new pathological entity in end-stage dementia. $10^{\text {th }}$ International Conference on Alzheimer's Disease and Related Disorders, Madrid, Spain. (2007) In: Alzheimer's Disease: New Advances Medimond International Proceedings 55-59. Pubmed $\mid$ Crossref $\mid$ Others

8. Aminoff, B.Z. End-stage Dementia: Aminoff Suffering Syndrome and Relief of Suffering Units. (2008) The Open Geriatr Med J 1: 29-32. Pubmed | Crossref $\mid$ Others

9. Aminoff, B.Z. End-Stage Dementia: Aminoff Suffering Syndrome and decubitus ulcers. (2012) Dementia 11 (4): 473-481.

Pubmed | Crossref $\mid$ Others

10. Alzheimer, A. Uber eine eigenartige Erkankung der Hirnrinde. (1907) Allgemeine Zeitschrift fur Psychiatrie 64: 146-148.

Pubmed $\mid$ Crossref $\mid$ Others

11. Aminoff, B.Z. Mrs. Auguste D \{eter\} demise in 1906 was in Aminoff Suffering Syndrome. (2014) Am J Alzheimers Dis Other Demen 29(3): 199-200.

Pubmed | Crossref | Others

12. Aminoff, B.Z. Mini-Suffering State Examination. IVth European Congress of Gerontology, Berlin, Germany [abstract]. (1999) Gerontol und Geriatr 32(2): 238.

Pubmed $\mid$ Crossref $\mid$ Others

13. Aminoff, B.Z., Purits, E., Noy, Sh., et al. Measuring the suffering of end-stage dementia: Reliability and validity of the Mini-Suffering State Examination. (2014) Arch Gerontol Geriatr 38(2): 123-130.

Pubmed | Crossref | Others

14. Koppitz, A., Waldboth, V., Dreizler, J., et al. Dying with dementia: most frequent symptoms. A review of the literature / Sterben mit Demenz: die häufigsten Symptome. Eine Literaturübersicht. (2015) International Journal of Health Professions 2(1): 49-63.

Pubmed | Crossref | Others

15. Eicher, S., Theill, N., Geschwindner, H., et al. The last phase of life with dementia in Swiss nursing homes: the study protocol of the longitudinal and prospective ZULIDAD study. (2016) BMC Palliat Care 15(1): 80 .

Pubmed | Crossref | Others

16. Anthea, I., Fiona, K., Charles, S., et al. Living with dementia in hospital wards: a comparative study of staff perceptions of practice and observed patient experience. (2016) Int J Older People Nurs 11(2): 94106.

Pubmed | Crossref | Others

17. van der Steen, J.T., Deliens, L., Koopmans, R.T., et al. Physicians' perceptions of suffering in people with dementia at the end of life. (2017) Palliat Support Care 23:1-13.

Pubmed | Crossref | Others
18. Cohen-Almagor, R. First Do No Harm: Euthanasia of Patients with Dementia in Belgium. (2016) J Med Philos. 41(1): 74-89.

Pubmed | Crossref | Others

19. Koppitz, A., Bosshard, G., Kipfer, S., et al. Decision-making in caring for people with dementia at the end of life in nursing homes. (2016) Int J Palliat Nurs 22(2): 68-75.

Pubmed | Crossref | Others

20. Glass, A.P. Family Caregiving and the Site of Care: Four Narratives About End-of-Life Care for Individuals with Dementia. (2016) J Soc Work End Life Palliat Care 12(1-2): 23-46.

Pubmed | Crossref | Others

21. Scott, H. The importance of spirituality for people living with dementia. (2016) Nurs Stand 30(25): 41-50.

Pubmed | Crossref | Others

22. Schols, R., Schipper, R., Brabers, A., et al. De Mini-Suffering State Exam (MSSE) onderzocht in een Nederlands verpleeghuis. (2003) Dementie (Nederlands) 27(5): 14-19.

Pubmed $\mid$ Crossref $\mid$ Others

23. Brtáňová, J. Paliatívna starostlivost' o pacienta v poslednom štádiu demencie. (2016) Paliat med liec Boles 9(1e): e5-e10.

Pubmed $\mid$ Crossref $\mid$ Others

24. Volicer, L., Hurley, A.C., Blasi, Z.V. Scales for evaluation of end-oflife care in dementia. (2001) Alzheimer Dis Assoc Disord 15(4): 194200.

Pubmed | Crossref | Others

25. Aminoff, B.Z. Mini-Suffering State Examination Scale: Possible key criterion for 6 months' survival and mortality of critically ill dementia patients. (2008) Am J Hosp Palliat Med 24(6): 470-704.

Pubmed | Crossref | Others

26. Aminoff, B.Z., Adunsky, A. Their last six months of life: Suffering and survival of end-stage dementia patients. (2006) Age Ageing 35(6): 597-601.

Pubmed | Crossref | Others

27. Aminoff, B.Z., Adunsky, A. Dying dementia patients: Too much suffering, too little palliation. (2004) Am J Alzheimers Dis Other Demen 19(4): 243-247.

Pubmed | Crossref | Others

28. Aminoff, B.Z., Adunsky, A. Dying dementia patients: Too much suffering, too little palliation. (2005) Am J Hosp Palliat Med 22(5): 344-348.

Pubmed | Crossref | Others

29. St.John, K. Preventing avoidable hospital admissions for people with advanced dementia. (2015) End Life J 5: 1 e900005.

Pubmed | Crossref $\mid$ Others

30. Aminoff, B.Z. Overprotection phenomenon with dying dementia patients. (2005) Am J Hosp Palliat Med 22(4): 247-248.

Pubmed | Crossref | Others

31. Aminoff, B.Z. Family overprotection phenomenon of dying dementia patients. 10th International Conference on Alzheimer's Disease and Related Disorders, Madrid, Spain, In: Alzheimer's Disease: New Advances, (2007) Medimond International Proceedings 687-691.

Pubmed | Crossref | Others

32. Aminoff, B.Z. Geriatrics D Refusal Phenomenon. 10th International Conference on Alzheimer's Disease and Related Disorders, Madrid, Spain, July 15-20, 2006, Madrid, Spain. In: Alzheimer's Disease: New Advances. (2007) Medimond International Proceedings 631-635.

Pubmed $\mid$ Crossref $\mid$ Others

33. Aminoff, B.Z. The New Israeli Law "The dying patient" and Relief of Suffering Units. (2007) Am J Hosp Palliat Med 24(1): 54-58.

Pubmed | Crossref | Others

34. Aminoff, B.Z. Relief of Suffering with Dementia Units. Innovations in care - the Israeli Perspective. (2009) Dementia (Special Issue) 8: 407-415.

Pubmed | Crossref | Others

35. Cassel, E.J. The nature of suffering and the goals of medicine. (1982) N Engl J Med 306(11): 639-645.

Pubmed | Crossref | Others 
36. Mitchell, S.L., Teno, J.M., Kiely, D.K., et al. The clinical course of advanced dementia. (2009) N Engl J Med 361(16): 1529-1538.

Pubmed | Crossref | Others

37. Krikorian, A., Limonero, J.T., Corey, M.T. Suffering assessment: a review of available instruments for use in palliative care. (2013) J Palliat Med 16(2): 130-142.

Pubmed | Crossref | Others

38. van Soest-Poortvliet, M.C., van der Steen, J.T., Zimmerman, S., et al. Measuring the quality of dying and quality of care when dying in long-term care settings: a qualitative content analysis of available instruments. (2011) J Pain Symptom Manage 42(6): 852-563.

Pubmed | Crossref | Others

39. Aminoff, B.Z. Entropic definition of human happiness and suffering. (2013) Philosophy Study 3: 609-618.

Pubmed | Crossref | Others

40. Cohen, L.W., van der Steen, J.T., Reed, D., et al. Family perceptions of end-of-lifecare for long-term care residents with dementia: differences between the United States and the Netherlands. (2012) J Am Geriatr Soc 60(6): 316-322.

Pubmed | Crossref $\mid$ Others

41. van Soest-Poortvliet, M.C., van der Steen, J.T., Zimmerman, S., et al. Psychometric properties of instruments to measure the quality of end-of-life care and dying for long-term care residents with dementia. (2012) Qual Life Res 21(4): 671-684.

Pubmed | Crossref | Others

42. MacAdam, D.B., Smith, M. An initial assessment of suffering in terminal illness. (1987) Palliat Med 1: 37-47.

Pubmed | Crossref $\mid$ Others

43. Buchi, S., Sensky, T. PRISM: Pictorial Representation of Illness and Self Measure. A brief nonverbal measure of illness impact and therapeutic aid in psychosomatic medicine. (1999) Psychosomatics 40(4): 314-320.

Pubmed $\mid$ Crossref $\mid$ Others

44. Baines, B.K., Norlander, L. The relationship of pain and suffering in a hospice population. (2000) Am J Hosp Palliat Care 17(5): 319-326. Pubmed | Crossref | Others

45. Ruijs, K.D., Onwuteaka-Philipsen, B.D., van der Wal, G., et al. Unbearability of suffering at the end of life: The development of a new measuring device, the SOS-V. (2009) BMC Palliat Care 8(1): 16.

Pubmed | Crossref | Others
46. Schulz, R., Monin, J.K., Czaja, S.J., et al. Measuring the experience and perception of suffering. (2010) Gerontologist 50(6): 774-784. Pubmed | Crossref | Others

47. Wilson, K.G., Graham, I.D., Viola, R.A., et al. Structured interview assessment of symptoms and concerns in palliative care. (2004) Can J Psychiat 49(6): 350-358.

Pubmed | Crossref | Others

48. Parker, D., Hodgkinson, B. A comparison of palliative care outcome measures used to assess the quality of palliative care provided in long-term care facilities: A systematic review. (2011) Palliat Med 25(1): 5-20.

Pubmed | Crossref | Others

49. Krikorian, A., Roma, J.P. Current dilemmas in the assessment of suffering in palliative care. (2015) Palliat Support Care 13(4): 10931101.

Pubmed | Crossref | Others

50. Kumar, S.P., Sisodia, V. Reporting of validation studies: A systematic review and quantitative analysis of research publications in palliative care journals. (2013) Saudi J Health Sci 2(3): 161-168.

Pubmed $\mid$ Crossref $\mid$ Others

51. Aminoff, B.Z. On mechanisms of human behaviour: The "Mind Blindness Phenomenon" in Philosophy, Religion, Science and Medicine. (2015) Philosophy Study 5: 167-77.

Pubmed $\mid$ Crossref | Others

52. Aminoff, B.Z. Not Calm and Aminoff Suffering Syndrome in Advanced Alzheimer's Disease. (2016) Am J Alzheimers Dis Other Demen 31(2): 169-180.

Pubmed | Crossref | Others

53. Aminoff, B.Z. Aminoff Suffering Syndrome - Challenge for Nursing Staff in End-of-Life Caring: Open Letter and Proposals. (2016) British Journal of Medicine and Medical Research 15(3): 1-8.

Pubmed | Crossref | Others
Ommega Online Publishers

Journal Name: Letters In Health and Biological Sciences

Journal Short Name: Lett Health Biol Sci
ISSN no: 2475-6245

E-mail: healthandbiosciences@ommegaonline.com

Website: www.ommegaonline.org 